\title{
Resuscitation by hyperbaric exposure from a venous gas emboli following laparoscopic surgery
}

Thomas Kjeld ${ }^{1,2^{*}}$, Egon G Hansen ${ }^{2}$, Nana G Holler ${ }^{3}$, Henrik Rottensten ${ }^{3}$, Ole Hyldegaard ${ }^{3}$ and Eric C Jansen ${ }^{3}$

\begin{abstract}
Venous gas embolism is common after laparoscopic surgery but is only rarely of clinical relevance. We present a 52 year old woman undergoing laparoscopic treatment for liver cysts, who also underwent cholecystectomy. She was successfully extubated. However, after a few minutes she developed cardiac arrest due to a venous carbon dioxide $\left(\mathrm{CO}_{2}\right)$ embolism as identified by transthoracic echocardiography and aspiration of approximately $7 \mathrm{ml}$ of gas from a central venous catheter. She was resuscitated and subsequently treated with hyperbaric oxygen to reduce the size of remaining gas bubbles. Subsequently the patient developed one more episode of cardiac arrest but still made a full recovery. The courses of events indicate that bubbles had persisted in the circulation for a prolonged period. We speculate whether insufficient $\mathrm{CO}_{2}$ flushing of the laparoscopic tubing, causing air to enter the peritoneal cavity, could have contributed to the formation of the intravascular gas emboli. We conclude that persistent resuscitation followed by hyperbaric oxygen treatment after venous gas emboli contributed to the elimination of intravascular bubbles and the favourable outcome for the patient.
\end{abstract}

Keywords: $\mathrm{CO}_{2}$ embolism, Cardiac arrest, Hyperbaric oxygen treatment, Laparoscopy

\section{Introduction}

Laparoscopic surgery with carbon dioxide $\left(\mathrm{CO}_{2}\right)$ insufflation affects circulatory, pulmonary, renal, splanchnic, and endocrine functions but such perturbations are, most often, of little clinical significance [1]. Yet cardiac arrest has been reported following 2-20 of 100,000 laparoscopic procedures [2], and cardiac arrest seems to be related to a vasovagal response following rapid peritoneal distension and gas embolism [3]. Human and animal studies of laparoscopic surgery indicate gas embolism in about half of the cases, as detected by transoesophageal echocardiography [4-6]. Symptomatic supportive care is the primary therapeutic modality for venous gas embolism (VGE), while hyperbaric oxygen therapy is the first line of treatment for arterial gas embolism $[7,8]$. Here, we report of a patient who survived significant gas embolism by aspiration of the embolus followed by hyperbaric oxygen treatment.

\footnotetext{
* Correspondence: thomaskjeld@dadlnet.dk

'Department of Cardiology, University of Copenhagen, Herlev Hospital, Herlev Ringvej 100 DK-2730, Denmark

${ }^{2}$ Department of Anaesthesiology and intensive care, University of Copenhagen, Herlev Hospital, Herlev Ringvej 100 DK-2730, Denmark Full list of author information is available at the end of the article
}

\section{Case report}

A female patient (52 years, $56 \mathrm{~kg}$, ASA II) underwent laparoscopic marsupialization for liver cysts and also cholecystectomy. The patient was undergoing treatment with thiazide diuretics and a renin-angiotensin inhibitor for hypertension but had no other illnesses as evaluated by routine laboratory tests. The patient was premedicated with oral dexamethasone $4 \mathrm{mg}$. Anaesthesia was induced with propofol $200 \mathrm{mg}$ and maintained with propofol and remifentanil. After induction of anaesthesia, oral intubation was facilitated with rocuronium $40 \mathrm{mg}$, which was increased to a total dose of $90 \mathrm{mg}$ guided by 'train of four' [9]. The ventilation was controlled with an inspired oxygen fraction $\left(\mathrm{FiO}_{2}\right)$ of 0.50 , end-tidal tension of carbon dioxide $\left(E T^{\prime}{ }_{\mathrm{CO} 2}\right)$ was between 28 and $34 \mathrm{mmHg}$ and a positive end-expiratory pressure (PEEP) of $5 \mathrm{~cm} \mathrm{H}_{2} \mathrm{O}$. Blood pressure was monitored noninvasively on the right arm and oxygen saturation was measured by a pulse oximeter.

Four trocars were inserted in the abdomen and one was connected to a $\mathrm{CO}_{2}$ source (Fig. 1). Intra-abdominal pressure was maintained $<12 \mathrm{mmHg}$ with the patient in a head-up tilted position. During dissection, the surgeon used an $A B C$ surgical system (Force Argon ${ }^{\mathrm{mm}}$ II; Valleylab ${ }^{\mathrm{mc}}$, 


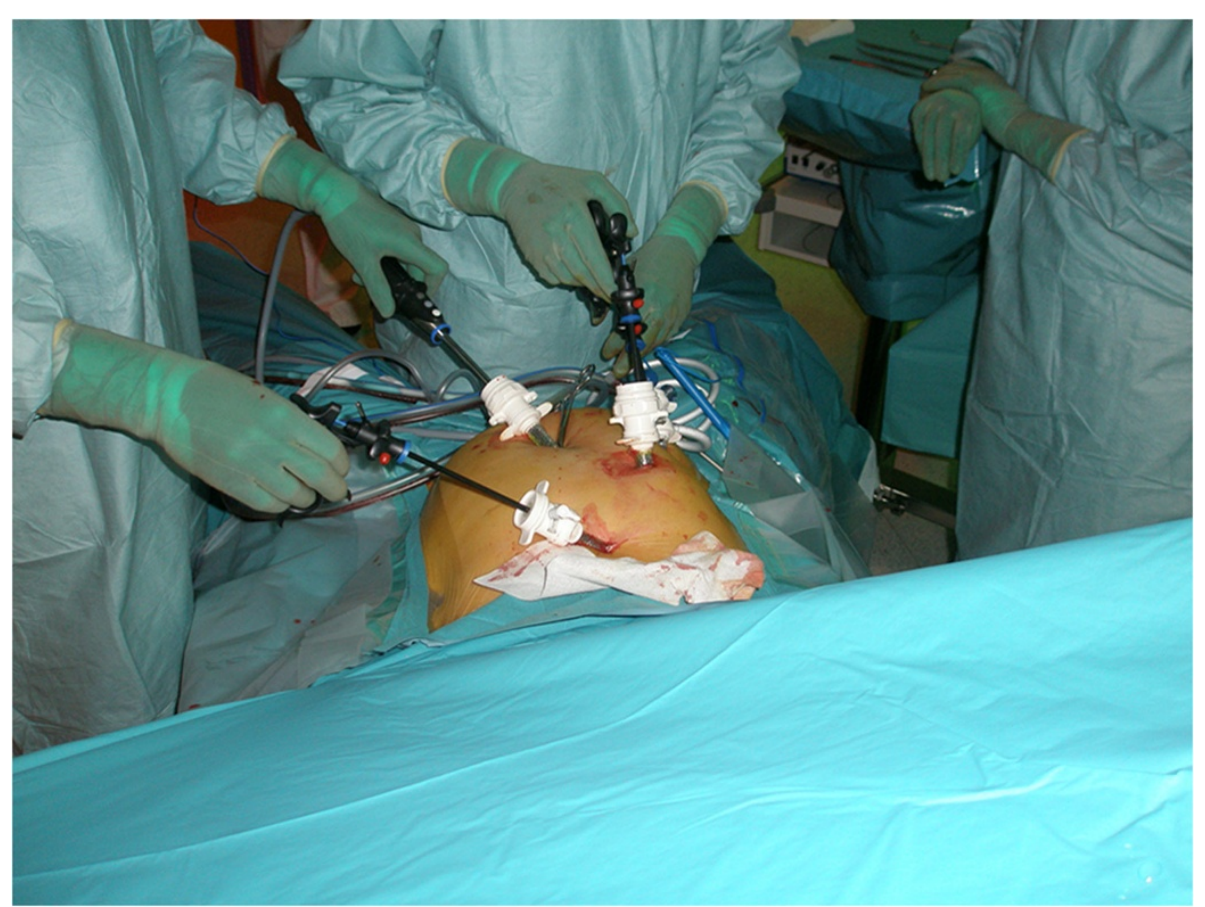

Figure 1 Laparoscopic procedure. Trocars are inserted in the abdomen (not from the presented case, picture kindly supplied by Dr. E. G. Hansen).

Boulder, CO). When awake after the operation, the patient complained of nausea. After a few minutes, the patient developed ventricular tachycardia and then pulseless electrical activity (PEA). Advanced resuscitation included uninterrupted manual compression, immediate intravenous administration of $1 \mathrm{mg}$ of adrenaline and $3 \mathrm{mg}$ of atropine intravenously, followed by $1 \mathrm{mg}$ of adrenaline every 2-4 min. The patient was reintubated and received 100\% oxygen. Transthoracic echocardiography showed minimal contraction of the ventricular walls. Gas bubbles were seen to move from the inferior caval vein into the right atrium and ventricle. The patient was placed in Trendelenburg's position and a central venous catheter was placed through the internal jugular vein. Approximately $7 \mathrm{ml}$ of gas was aspirated through the catheter. Resuscitation was successful after $40 \mathrm{~min}$ and she was transferred to the intensive care unit (ICU) with assisted mechanical ventilation: PEEP $13 \mathrm{~cm} \mathrm{H}_{2} \mathrm{O}$ and a $\mathrm{FiO}_{2}$ of 1.0. Frothy pink sputum was seen in the tracheal tube and a chest X-ray showed bilaterally pulmonary oedema (Fig. 2). Blood pressure was measured by a radial arterial catheter and maintained at 90/ $50 \mathrm{mmHg}$ by intravenous infusion of noradrenaline $25-50 \mu \mathrm{g} / \mathrm{kg} / \mathrm{h}$.

The patient was referred to a nearby hospital and treated in a hyperbaric chamber at a pressure of 2.8 ATA. The patient was ventilated with $100 \%$ oxygen. Within $2 \mathrm{~h}$ and $37 \mathrm{~min}$, the fluid balance was $1000 \mathrm{ml}$ positive and the inotropic medication was discontinued when systolic pressure was $140 \mathrm{mmHg}$. The patient was sedated with fentanyl $2 \mathrm{ml} / \mathrm{h}$ and propofol $20 \mathrm{ml} / \mathrm{h}$ [10] and by then no longer had frothy pink sputum. When the pressure was lowered to 1.9 ATA the patient developed non-sustained ventricular fibrillation followed by bradycardia.

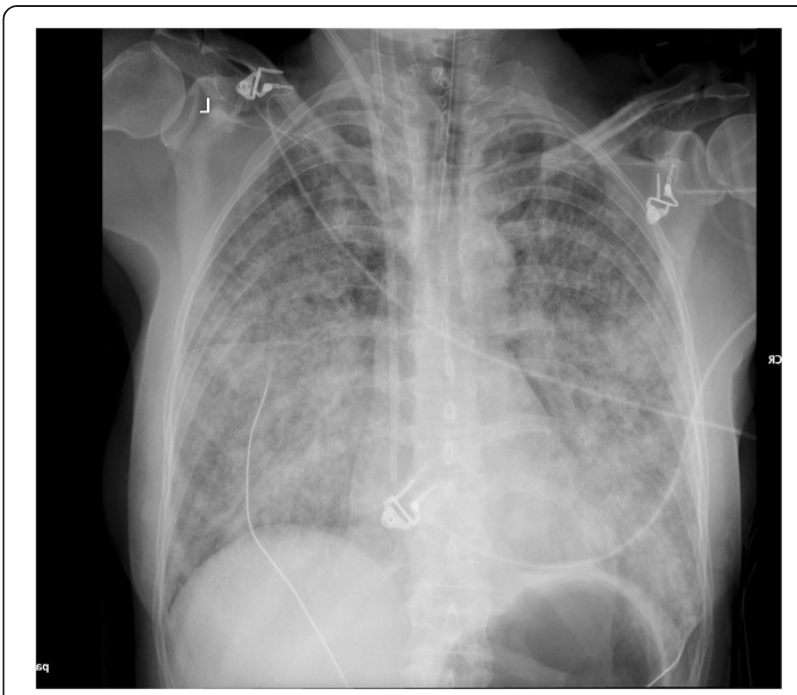

Figure $2 \mathrm{X}$-ray of the chest of the patient in the presented case showing bilaterally pulmonary oedema. 
It was believed that the ventricular fibrillation and subsequent cardiac arrest was a result of reperfusion rather than VGE and the hyperbaric treatment was therefore terminated.

The patient was referred to the ICU where, on arrival, she again developed cardiac arrest with PEA. Treatment was with adrenaline $1 \mathrm{mg}$, atropine $3 \mathrm{mg}$, and uninterrupted manual compression while mechanical ventilation with $100 \%$ oxygen was continued. Transthoracic echocardiography showed no movement of the ventricular walls and extracorporeal membrane oxygenation was considered, while adrenaline administration was repeated every 2-4 min. The patient then went into ventricular fibrillation, but after one biphasic direct current shock of $200 \mathrm{~J}$, return of cardiac function was obtained after $18 \mathrm{~min}$. The patient was then monitored according to a hypothermia algorithm that included continuous ECG, a central venous catheter and an arterial catheter. Temperature was monitored using a Foley catheter. Goals of treatment were a mean arterial pressure (MAP) of $65-100 \mathrm{mmHg}$ (by continuous dopamine infusion, $2-10 \mu \mathrm{g} / \mathrm{kg} / \mathrm{min}$ ), heart rate $40-90 \mathrm{~min}-{ }^{1}$, central venous pressure $2-10 \mathrm{mmHg}$, blood glucose $4.5-6.1 \mathrm{mmol} /$ $\mathrm{L}$, and diuresis $>1 \mathrm{~mL} / \mathrm{kg} / \mathrm{h}$. Active cooling was initiated with ice packs and infusion of $30 \mathrm{~mL} / \mathrm{kg}$ of $4^{\circ} \mathrm{C}$ Ringer's solution as well as continued therapeutic surface cooling using an Allon Thermowrap ${ }^{\text {TM }}$ (MTRE, Israel). The target core temperature was $32.5-35.5^{\circ} \mathrm{C}$ and it was maintained for $24 \mathrm{~h}$ with subsequent rewarming by $0.5^{\circ} \mathrm{C}$ per hour until normothermia. Meanwhile, the patient was sedated to a Ramsey score 6 (propofol $0.3-4.0 \mathrm{mg} / \mathrm{kg} / \mathrm{h}$, fentanyl $100 \mu \mathrm{g} / \mathrm{h}$ ) and paralysis during muscle shivering (cisatracurium, $0.06-0.12 \mathrm{mg} / \mathrm{kg} / \mathrm{h}$ ) [11].

On post-operative day (POD) 1 , arterial blood gas analysis and chest X-ray findings were normal. On POD 2, the patient was extubated and transferred to a cardiology unit and she made a full recovery on POD 4. Repeated transthoracic echocardiography showed a normal ejection fraction, no valvulopathy, pulmonary hypertension, or pericardial exudations, but a possible small ventricular septum defect. ECG showed no sign of infarction. Ultrasonography of the liver revealed no sequelae and clinical neurological assessment was normal.

\section{Discussion}

The risk of iatrogenic gas embolism is low. Three cases per 100,000 may be in need of hyperbaric treatment for gas embolisms and only 7/4,727,496 cases are described as being caused by laparoscopic surgery with intraperitoneal insufflation of $\mathrm{CO}_{2}$ [8].

However, in the case presented here, the patient went through laparoscopic liver surgery and cholecystectomy with an inherent risk of VGE, since liver veins are little prone to collapse in the supine position $[12,13]$. The effect of VGE depends on the rate of $\mathrm{CO}_{2}$ infusion and its volume [14]. For adults, the potentially lethal volume is estimated at $200-300 \mathrm{ml}$ or $3-5 \mathrm{~mL} / \mathrm{kg}$ [15]. The effect VGE also depends on whether the patient is breathing spontaneously, yielding a negative thoracic pressure during inspiration and hence facilitating air entrapment, or whether the patient is under positive pressure ventilation, possibly supplemented by PEEP.

The essential pathological factor is pulmonary gas embolism. Tachyarrhythmias are common following VGE and the electrocardiogram demonstrates a right heart strain pattern as well as ST-T changes, and blood pressure decreases with cardiac output. Pulmonary symptoms following VGE include dyspnoea, continuous coughing, and chest pain. Gasping for air reduces the intrathoracic pressure and may be a sign of air entrapment. Pulmonary signs of VGE include rales, wheezing, and tachypnoea. The central nervous system may be affected by VGE by cardiovascular collapse secondary to reduced cardiac output from right ventricular failure or myocardial ischemia, which rapidly results in cerebral hypoperfusion [16]. In the present case, the VGE did probably not pass the interventricular septum, as no gas was seen on the left side of the heart and the patient recovered without any apparent neurological deficits despite three episodes of cardiac arrest and prolonged resuscitation.

The most widely used gas for laparoscopic procedures is $\mathrm{CO}_{2}$ [2]. $\mathrm{CO}_{2}$ is inexpensive, non-flammable and has the additional advantage of being readily available. Since $\mathrm{CO}_{2}$ has a high Ostwald's solubility coefficient in blood and tissue $(\mathrm{L}=0.54 \mathrm{ml}$ per $\mathrm{ml}$ whole blood [17]), and since blood holds a high buffering capacity for $\mathrm{CO}_{2}$, VGE's consisting of $\mathrm{CO}_{2}$ are quickly absorbed should they occur. When insufflated into the abdominal cavity, $\mathrm{CO}_{2}$ diffuses across the peritoneum, and, more importantly, is carried by the circulation to the lungs and expired. However, as demonstrated by SP Taylor and GM Hoffman, substantial amounts of air (containing $79 \%$ of the insoluble $\mathrm{N}_{2}$ [17]) may be insufflated into the peritoneal cavity from the tubing, if the system is not adequately purged with $\mathrm{CO}_{2}$ gas before insertion $[18,19]$. The VGE in the present case may therefore be a combination of a $\mathrm{CO}_{2}$ and air embolism. Whether or not air contamination of the peritoneal cavity was a matter of significance in the present case remains speculative, as we were not capable of measuring the gas content of the bubbles aspirated through the central venous catheter. Although surgeons routinely purge laparoscopic tubing systems with $\mathrm{CO}_{2}$ gas, as was the standard operational procedure in the present case, surgeons and anaesthetists should be aware of the risk of simultaneous $\mathrm{CO}_{2}$ and air embolisms during these procedures. 
In the case of air bubble contamination during laparoscopic procedures, AB Branger et al. [16] have demonstrated that microscopic $\mathrm{N}_{2}$ bubbles $(50 \mathrm{nl}$ ) having a cylindrical shape in the capillary vessels will dissolve in $>300 \mathrm{~min}$. Larger emboli, in the size of millilitres, would require even longer resorption time if left untreated, and air bubbles have been observed to persist within the vasculature for more than $48 \mathrm{~h}$ [20]. The molar flux of any permeating ideal gas species present in blood and tissues obeys Fick's first law of diffusion $[21,22]$ whereby each gas will have a flux through the surface area of the gas emboli, driven by the partial pressure difference between the inside of the emboli and surrounding tissue and blood. It is conceivable that larger gas emboli of $\mathrm{CO}_{2}$ may persist in blood vessels and tissues long enough for them to equilibrate with other gases present in blood and tissues (i.e. oxygen, nitrogen and water vapour), thereby increasing the bubble resolution time considerably, as demonstrated by Barrera et al. [23]. During anaerobic metabolism, such as with gas embolism blocking microcirculation, large amounts of $\mathrm{CO}_{2}$ would be liberated from bicarbonate stores of blood and tissue, resulting in high levels of local $\mathrm{PCO}_{2}$, thereby reducing the partial pressure gradient of $\mathrm{CO}_{2}$ from the emboli to blood, which could contribute considerably to the bubble volume or reduce the rate of $\mathrm{CO}_{2}$ disappearance from the emboli [24].

If large iatrogenic VGE causes hemodynamic changes, treatment in a hyperbaric chamber combined with 100\% oxygen breathing is well indicated $[14,25,26]$. If available, such treatment will often consist of compression of the patient to $285 \mathrm{kPa}$ (i.e. $2.8 \mathrm{~atm}$ abs) breathing oxygen. The purpose is to 1) reduce the intravascular bubble size by compression of the gas phase according to Boyles Law, 2) maximize gas partial pressure gradients from bubbles and tissues to blood thereby increasing the speed of bubble elimination, and 3) to introduce systemic hyperoxia in an otherwise hypoxic tissue. The first goal is almost immediately achieved by compression regardless of the breathing mixture used, whereas oxygen breathing would achieve the latter two goals. An arterial partial pressure of oxygen greater than $2000 \mathrm{mmHg}$ is readily achieved. Hyperoxia also increases the distance of oxygen diffusion in tissues and offsets the embolic insult to the microvasculature. Hyperbaric oxygen is the treatment of choice for arterial gas embolism [14]. Time is important, but delayed treatment in a hyperbaric chamber may still be indicated to ameliorate the patient's condition and reduce long term neurological sequelae.

Apparently, the patient benefited from the hyperbaric treatment. The courses of events suggest that bubbles had persisted in the circulation for a prolonged period, and that persistent resuscitation followed by hyperbaric treatment after VGE contributed to their elimination. The second cardiac arrest might have been avoided, if the pressure in the chamber had been increased instead of reducing the pressure to 1.9 ATA.

\section{Consent}

The patient has given verbal and written consent to the publication of her case report.

\section{Competing interests \\ The author(s) declare that they have no competing interests.}

\section{Authors' contributions}

$\mathrm{OH}$ contributed to the drafting of the manuscript including interpretation of observed clinical data as well as search of and adding of references. TJ contributed in writing and editing of manuscript, search of and adding references, correspondance with co-authors and adjustments according to comments from editors from SJTREM and biomed central, adding figure 2 and observed clinical data. ECJ contributed to the drafting of the manuscript including interpretation of observed clinical data as well as search of and adding of references. HR contributed to the drafting of the manuscript including interpretation of observed clinical data. NGH contributed to the interpretation of observed clinical data. All authors read and approved the final manuscript.

\section{Acknowledgements}

The authors wish to thank Professor Niels H. Secher, medical secretary Karen O'Neill and medical translator Lisbet Guhle for comments.

\section{Author details}

'Department of Cardiology, University of Copenhagen, Herlev Hospital, Herlev Ringvej 100 DK-2730, Denmark. ${ }^{2}$ Department of Anaesthesiology and intensive care, University of Copenhagen, Herlev Hospital, Herlev Ringvej 100 DK-2730, Denmark. ${ }^{3}$ The Hyperbaric Unit, Department of Anaesthesiology, Centre of Head and Orthopaedics, Rigshospitalet, University of Copenhagen, Blegdamsvej 9 2100Copenhagen $\varnothing$, Denmark.

Received: 13 November 2011 Accepted: 11 July 2012

Published: 3 August 2012

\section{References}

1. Gutt CN, Oniu T, Mehrabi A, Schemmer P, Kashfi A, Kraus T, Buchler MW: Circulatory and respiratory complications of carbon dioxide insufflation. Dig Surg 2004, 21:95-105

2. Magrina JF: Complications of laparoscopic surgery. Clin Obstet Gynecol 2002, 45:469-480.

3. Galizia G, Prizio G, Lieto E, Castellano P, Pelosio L, Imperatore V, Ferrara A, Pignatelli C: Hemodynamic and pulmonary changes during open, carbon dioxide pneumoperitoneum and abdominal wall-lifting cholecystectomy. A prospective, randomized study. Surg Endosc 2001, 15:477-483.

4. Fors D, Eiriksson K, Arvidsson D, Rubertsson S: Gas embolism during laparoscopic liver resection in a pig model: frequency and severity. $\mathrm{Br} \mathrm{J}$ Anaesth 2010, 105:282-288.

5. Schmandra TC, Mierdl S, Hollander D, Hanisch E, Gutt C: Risk of gas embolism in hand-assisted versus total laparoscopic hepatic resection. Surg Technol Int 2004, 12:137-143.

6. Hong JY, Kim WO, Kil HK: Detection of subclinical CO2 embolism by transesophageal echocardiography during laparoscopic radical prostatectomy. Urology 2010, 75:581-584.

7. Fukaya E, Hopf HW: HBO and gas embolism. Neurol Res 2007, 29:142-145.

8. Bessereau J, Genotelle N, Chabbaut C, Huon A, Tabah A, Aboab J, Chevret S, Annane D: Long-term outcome of iatrogenic gas embolism. Intensive Care Med 2010, 36:1180-1187.

9. White PF: Use of cerebral monitoring during anaesthesia: effect on recovery profile. Best Pract Res Clin Anaesthesiol 2006, 20:181-189.

10. Weaver LK: Monoplace hyperbaric chamber use of U.S. Navy Table 6: a 20-year experience. Undersea Hyperb Med 2006, 33:85-88.

11. Bro-Jeppesen J, Kjaergaard J, Horsted TI, Wanscher MC, Nielsen SL, Rasmussen LS, Hassager C: The impact of therapeutic hypothermia on 
neurological function and quality of life after cardiac arrest. Resuscitation 2009, 80:171-176.

12. Rasmussen A, Skak C, Kristensen M, Ott P, Kirkegaard P, Secher NH: Preserved arterial flow secures hepatic oxygenation during haemorrhage in the pig. J Physiol 1999, 516(Pt 2):539-548.

13. Lautt WW, Greenway CV: Conceptual review of the hepatic vascular bed. Hepatology 1987, 7:952-963.

14. Muth CM, Shank ES: Gas embolism. N Engl J Med 2000, 342:476-482.

15. Toung TJ, Rossberg Ml, Hutchins GM: Volume of air in a lethal venous air embolism. Anesthesiology 2001, 94:360-361.

16. Branger AB, Lambertsen CJ, Eckmann DM: Cerebral gas embolism absorption during hyperbaric therapy: theory. J Appl Physiol 2001, 90:593600.

17. Lango T, Morland T, Brubakk AO: Diffusion coefficients and solubility coefficients for gases in biological fluids and tissues: a review. Undersea Hyperb Med 1996, 23:247-272.

18. Taylor SP, Hoffman GM: Detection of Nitrogen in Laparoscopic Insufflation Gas by Raman Spectroscopy (Ohmeda Rascal-2) (Abstract). In proceedings ofAm Soc Anesthesiol.; 2010. A246.

19. Taylor SP, Hoffman GM: Insufflation Technique Affects Nitrogen Concentration in Gases during Laparoscopic Procedures. In procedings of Am Soc Anesthesiol.; 2010. A247.

20. Sadan O, Adler M, Ezra S, Zakut H: Air embolism due to pulmonary barotrauma in a patient undergoing cesarean section. Acta Obstet Gynecol Scand 1991, 70:511-513.

21. Burkard ME, Van Liew HD: Simulation of exchanges of multiple gases in bubbles in the body. Respir Physiol 1994, 95:131-145.

22. Van Liew HD, Hlastala MP: Influence of bubble size and blood perfusion on absorption of gas bubbles in tissues. Respir Physiolo 1969, 7:111-121.

23. Barrera F, Durant TM, Lynch PR, Oppenheimer MJ, Stauffer HM, Stewart GH: In vivo visualization of intracardiac structures with gaseous carbon dioxide; cardiovascular-respiratory effects and associated changes in blood chemistry. Am J Physiol 1956, 186:325-334.

24. Van Liew HD, Conkin J, Burkard ME: The oxygen window and decompression bubbles: estimates and significance. Aviat Space Environ Med 1993, 64:859-865.

25. Mirski MA, Lele AV, Fitzsimmons L, Toung TJ: Diagnosis and treatment of vascular air embolism. Anesthesiology 2007, 106:164-177.

26. Muth CM, Shank ES, Larsen B: Severe diving accidents: physiopathology, symptoms, therapy. Anaesthesist 2000, 49:302-316.

doi:10.1186/1757-7241-20-51

Cite this article as: Kjeld et al:: Resuscitation by hyperbaric exposure from a venous gas emboli following laparoscopic surgery. Scandinavian Journal of Trauma, Resuscitation and Emergency Medicine 2012 20:51.

\section{Submit your next manuscript to BioMed Central and take full advantage of:}

- Convenient online submission

- Thorough peer review

- No space constraints or color figure charges

- Immediate publication on acceptance

- Inclusion in PubMed, CAS, Scopus and Google Scholar

- Research which is freely available for redistribution

Submit your manuscript at www.biomedcentral.com/submit
Biomed Central 